\title{
Complications related to the use of spinal cord stimulation for managing persistent postoperative neuropathic pain after lumbar spinal surgery
}

\author{
Mohammed F. Shamji, MD, PhD, ${ }^{1,2}$ Harrison J. Westwick, MD, MSc, ${ }^{3}$ and Robert F. Heary, MD ${ }^{4}$ \\ 'Department of Surgery, University of Toronto; '2Division of Neurosurgery, Toronto Western Hospital, Toronto, Ontario; \\ ${ }^{3}$ Department of Surgery, Université de Montréal, Quebec, Canada; and ${ }^{4}$ Rutgers New Jersey Medical School, Newark, New \\ Jersey
}

\begin{abstract}
OBJECT Structural spinal surgery yields improvement in pain and disability for selected patients with spinal stenosis, spondylolisthesis, or a herniated intervertebral disc. A significant fraction of patients exhibit persistent postoperative neuropathic pain (PPNP) despite technically appropriate intervention, and such patients can benefit from spinal cord stimulation (SCS) to alleviate suffering. The complication profile of this therapy has not been systematically assessed and, thus, was the goal of this review.
\end{abstract}

METHODS A comprehensive literature search was performed to identify prospective cohorts of patients who had PPNP following structurally corrective lumbar spinal surgery and who underwent SCS device implantation. Data about study design, technique of SCS lead introduction, and complications encountered were collected and analyzed. Comparisons of complication incidence were performed between percutaneously and surgically implanted systems, with the level of significance set at 0.05 .

RESULTS Review of 11 studies involving 542 patients formed the basis of this work: 2 randomized controlled trials and 9 prospective cohorts. Percutaneous implants were used in 4 studies and surgical implants were used in 4 studies; in the remainder, the types were undefined. Lead migration occurred in $12 \%$ of cases, pain at the site of the implantable pulse generator occurred in $9 \%$ of cases, and wound-related complications occurred in $5 \%$ of cases; the latter 2 occurred more frequently among surgically implanted devices.

CONCLUSIONS Spinal cord stimulation can provide for improved pain and suffering and for decreased narcotic medication use among patients with PPNP after lumbar spinal surgery. This study reviewed the prospective studies forming the evidence base for this therapy, to summarize the complications encountered and, thus, best inform patients and clinicians considering its use. There is a significant rate of minor complications, many of which require further surgical intervention to manage, including lead migration or implant infection, although such complications do not directly threaten patient life or function.

http://thejns.org/doi/abs/10.3171/2015.7.FOCUS15260

KEY WORDS failed-back surgery syndrome; persistent postoperative neuropathic pain; spinal cord stimulation; complications

$\mathrm{L}$ UMBAR degenerative disease can cause symptomatic neurogenic claudication or lumbar radiculopathy by both mechanical distortion and biochemical irritation of apposed neural elements. Surgery may be indicated to provide for structural remedy in cases where pain is refractory to conservative management or where there is significant or progressive motor deficit, and such intervention can provide for improvements in pain, disability, and quality of life in the majority of patients. ${ }^{34-36}$
Nevertheless, a significant fraction of patients report variable experiences of neuropathic pain, a maladaptive process whereby normal sensory signaling is altered so that pain is felt in the absence of nociceptive stimulus. After excluding or addressing recurrent segmental disease, adjacent-segment disease, and instability, the management of such persistent postoperative neuropathic pain (PPNP) involves a multitiered approach involving pharmacological, interventional, and surgical maneuvers. ${ }^{34-36}$

ABBREVIATIONS CMM = conventional medical management; $E D H=$ epidural hematoma; $P P N P=$ persistent postoperative neuropathic pain; RCT = randomized controlled trial; SCS = spinal cord stimulation. 
Spinal cord stimulation (SCS) is one of the surgical procedures that has the potential to improve suffering among patients with PPNP. Through controlled delivery of electrical impulses to the dorsal columns of the spinal cord, the putative mechanisms are thought to include both orthodromic and antidromic activation of A- $\beta$ fibers, recruitment of supraspinal nuclei to augment descending inhibitory impulses, and altered CSF neurochemistry. 16,17,23,26 Patients are commonly exposed to trial stimulation using an external neurostimulator that activates either percutaneously or surgically implanted leads, after which they are implanted with an implantable pulse generator if appropriate analgesia is achieved. Figure 1 presents an illustrative example of a patient implanted with such a device. With appropriately selected patients at centers with interdisciplinary expertise, the trial-to-implant conversion rates can be quite encouraging: in the $65 \%-80 \%$ range for various diagnoses, ${ }^{15}$ although from a nationwide perspective, the actual conversion rate remains less encouraging at approximately $41 \%$.

The utility of this technology has been demonstrated in prospective randomized and observational studies, and in systematic literature reviews for various pathologies, including PPNP after structurally corrective lumbar spinal surgery, ${ }^{6}$ complex regional pain syndrome, ${ }^{27}$ chronic inoperable limb ischemia, ${ }^{31}$ treatment-refractory angina, ${ }^{28}$ and painful diabetic neuropathy. ${ }^{3}$ Despite its proven efficacy for the PPNP population, there have been a few small studies that reported on the risk experienced by patients undergoing such intervention specifically in the context of managing neuropathic pain after lumbar spinal surgery, and whether those rates of complication are variable by surgical technique. While percutaneous placement of single-column electrode leads may be less invasive, surgical placement of multicolumn paddles may enhance outcome and protect against device migration. ${ }^{21,33}$ The goal of this narrative review is to examine the evidence supporting safety of the SCS technique among patients being managed for PPNP after lumbar spinal surgery for degenerative disease.

\section{Methods}

\section{Electronic Literature Search}

We conducted a systematic search in MEDLINE for literature published through December 2014, limiting the search results to human studies published in the English language. Reference lists of key articles were also systematically checked to identify additional eligible articles. The key question focused on the complications of SCS procedures specifically for the management of neuropathic pain after structurally corrective spinal surgery. Terms for this condition have variably included failed-back surgery syndrome, postlaminectomy pain syndrome, and PPNP. The study population was over the age of 18 years and we included only prospective studies of randomized controlled trial (RCT) or observational cohort design. Case reports or case series that consisted of fewer than 10 patients were excluded. Other studies excluded were animal, cadaveric, and biomechanical studies, and those that did not report complications. Table 1 summarizes this selection process.

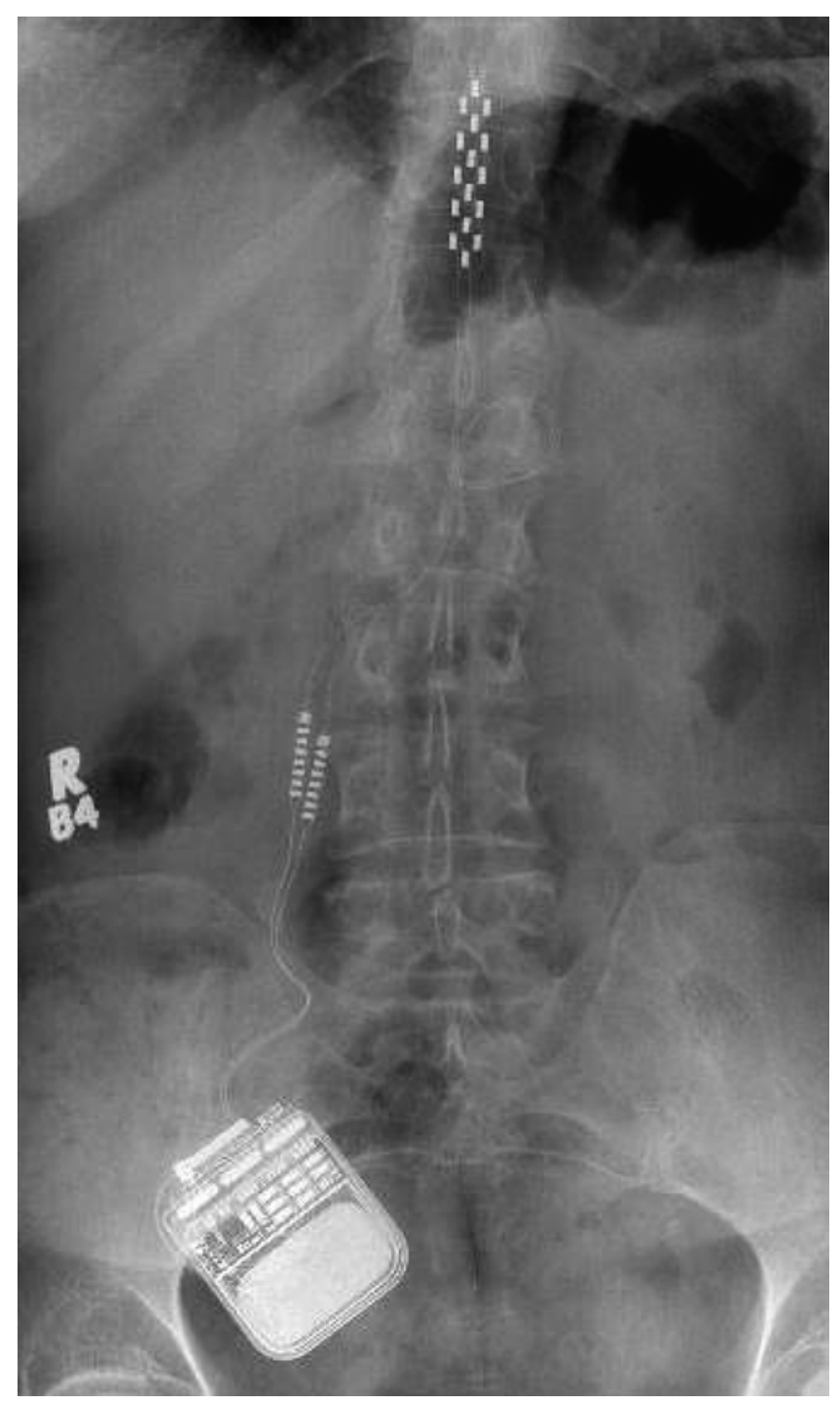

FIG. 1. Anteroposterior radiograph of a patient in whom an SCS device was placed for the management of PPNP. The paddle lead is attached via extensions to an implantable pulse generator in a buttock pocket.

\section{Data Extraction and Analysis}

We extracted the following data from the included articles: study design, patient demographics, surgical technique (percutaneous vs open implantation), and perioperative and follow-up complications. Summary statistics regarding overall reported complication rates were generated by pooled estimates based on study size. These are reported as related to implants, therapeutic efficacy, and biological types. Variability in complications between implants placed surgically and percutaneously was assessed at the 0.05 level of significance.

\section{Results}

\section{Study Selection}

The search strategy identified 752 articles, of which 586 represented discrete patient cohorts. Forty-eight were selected for full-text review, from which 37 were fur- 
TABLE 1. PICO summary of inclusion and exclusion criteria

\begin{tabular}{llc}
\hline PICO Category & \multicolumn{1}{c}{ Inclusion } & Exclusion \\
\hline Patient & $\begin{array}{c}\text { Age }>\text { 18 yrs, SCS for } \\
\text { PPNP after lumbar } \\
\text { spinal surgery }\end{array}$ & $\begin{array}{c}\text { Other indications for } \\
\text { SCS }\end{array}$ \\
\hline \multicolumn{3}{c}{$\begin{array}{c}\text { SCS implant for neuro- } \\
\text { pathic pain }\end{array}$} \\
\hline Comparison & $\begin{array}{c}\text { Percutaneous vs surgi- } \\
\text { cal leads }\end{array}$ \\
\hline Outcome & Complications \\
\hline Study design & $\begin{array}{c}\text { Prospective RCTs or } \\
\text { cohort studies }\end{array}$ & $\begin{array}{c}\text { Case reports, studies } \\
\text { w/<10 patients, } \\
\text { retrospective studies, } \\
\end{array}$ \\
& & cadaver studies \\
\hline
\end{tabular}

$\mathrm{PICO}=$ population, intervention, comparison intervention, outcome measures.

ther excluded on the basis of reporting only about trials, performing retrospective analysis, no reporting of complications, or SCS therapy was not specifically used for the management of neuropathic pain after lumbar spinal surgery. Consequently, 11 articles were found suitable for reporting complications, of which 2 were arms of randomized controlled trials ${ }^{11,19}$ and 9 represented prospective observational studies. ${ }^{1,5,8,14,20,22,24,30,32}$ The flow of this process is summarized in Fig. 2.

\section{Complications}

Table 2 summarizes the studies included for analysis of perioperative and long-term complications found on follow-up. Of the 11 studies, there was a total of 542 patients with implanted SCS devices who were followed up for a study median of 24 months and a patient mean of 19 months. The overall duration of follow-up was longer for the RCTs (patient mean 29 months vs 18 months; $p$ $<0.05$ ). Among 8 studies that reported the technique by which the SCS leads were introduced (4 surgically and 4 percutaneously), the overall duration of follow-up was longer for the surgically introduced systems (patient mean 21 months vs 14 months; $p<0.05$ ).

In the 542 patients followed in this work, there were 184 complications. Of these, 74 were related to the SCS device itself, 69 were related to the therapy, and 41 represented biological complications.

Table 3 summarizes complications related to the SCS device. The most common among these included lead migration or misplacement $(12.2 \%$; range $5 \%-21 \%)$ with no significant difference among systems that were implanted surgically (14\%) versus percutaneously (12\%). Other device-related complications included implantable pulse generator failure $(0.4 \%)$, migration $(0.2 \%)$, and wire breakage $(1.5 \%)$.

Therapy-related complications are summarized in Table 4. Loss of therapeutic efficacy was observed in $4 \%$ of cases (range $0 \%-14 \%$ ), although this was only described among patients with devices placed percutaneously. Pain at the sites of device implantation occurred in $9 \%$ of cases, and this was more frequent among those devices placed

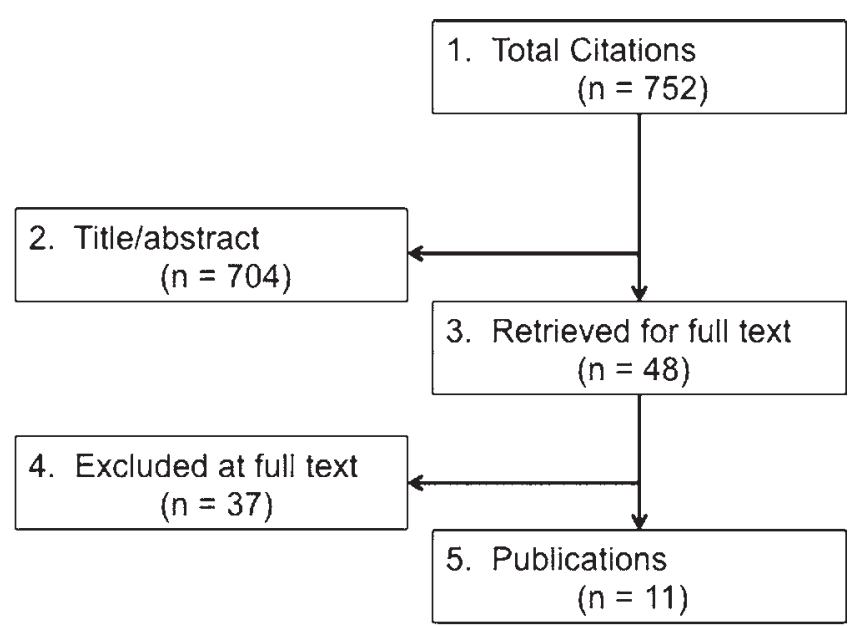

FIG. 2. Study selection flow chart for search for articles pertaining to the use of SCS for managing PPNP after structurally corrective spinal surgery.

surgically $(12 \%)$ than those placed percutaneously (7\%; $\mathrm{p}<0.05)$.

Table 5 summarizes the biological complications associated with SCS therapy. Wound complications of infection and dehiscence were observed in 5\% of patients (range 0\%-14\%). Such problems were noted more frequently among devices that were placed surgically (5\%) than those placed percutaneously $(2 \% ; \mathrm{p}<0.05)$.

\section{Discussion}

Low-back pain remains one of the dominant complaints for which patients seek medical attention. Surgical intervention can provide for improvements in pain and disability, and expedite return to work in appropriately selected patients; however, there remains a significant fraction of patients who exhibit PPNP and for whom conservative management strategies fail to provide relief. This condition can cause substantial pain and disability. In RCTs, neuromodulation in the form of SCS has demonstrated effectiveness in controlling the pain and reducing narcotic use in patients with persistent neuropathic pain following structurally corrective spinal surgery. ${ }^{12,19}$ This can be done cost effectively with the cost offset by postimplant health care use and return to work,,$^{9,18,29}$ although the same benefit has not been reproducible in the workers' compensation setting. ${ }^{30}$ As the number of index spine surgical procedures continues to grow to address increasing need among both active and aging populations, there is a need to better understand the safety profile of these procedures that are used to intervene when the index decompression or fusion procedure does not alleviate suffering.

The 2 RCTs examining this technology for PPNP compared the use of SCS technology either with conventional medical management (CMM) or further structural reoperation. Kumar and coworkers ${ }^{12}$ compared SCS and $\mathrm{CMM}$ and found that substantial pain relief was observed among $58 \%$ and $17 \%$ of patients, respectively, with prominent improvements noted for leg pain and no durable differences observed for back pain. North and coworkers ${ }^{19}$ 
TABLE 2. Summary of prospective studies detailing complications of SCS use for patients with PPNP

\begin{tabular}{|c|c|c|c|c|c|c|}
\hline Authors \& Year & $\begin{array}{c}\text { No. of } \\
\text { Patients }\end{array}$ & Study Type & Funding & $\begin{array}{l}\text { Implantation } \\
\text { Technique }\end{array}$ & $\begin{array}{l}\text { Follow-Up } \\
\text { (mos) }\end{array}$ & $\begin{array}{l}\text { No. of Complications } \\
\text { (rate [\%]) }\end{array}$ \\
\hline Rigoard et al., 2015 & 76 & Prospective & None reported & Surgical & 24 & $2(3)$ \\
\hline Al-Kaisy et al., 2014 & 83 & Prospective & Industry (Nevro Corp.) & Not described & 24 & $20(24)$ \\
\hline Van Buyten et al., 2013 & 82 & Prospective & Industry (Nevro Corp.) & Percutaneous & 6 & $49(60)$ \\
\hline Logé et al., 2013 & 21 & Prospective & None reported & Percutaneous & 40 & $8(38)$ \\
\hline Kinfe et al., 2012 & 81 & Prospective & None reported & Percutaneous & 12 & $11(14)$ \\
\hline Turner et al., 2010 & 28 & Prospective & NIH, WSDLI & Not described & 24 & $20(71)$ \\
\hline Kumar et al., 2008 & 42 & $\mathrm{RCT}$ & Industry (Medtronic) & Not described & 24 & $34(81)$ \\
\hline Duyvendak, 2007 & 20 & Prospective & None reported & Surgical & 12 & $16(80)$ \\
\hline Oakley et al., 2006 & 56 & Prospective & Industry (Medtronic) & Surgical & 12 & $14(25)$ \\
\hline North et al., $2005^{20}$ & 20 & Prospective & $\begin{array}{l}\text { Industry (Advanced Neuromodulation } \\
\text { Systems) }\end{array}$ & Percutaneous & 27 & $6(30)$ \\
\hline North et al., $2005^{19}$ & 33 & RCT & Industry (Medtronic) & Surgical & 36 & $3(9)$ \\
\hline
\end{tabular}

$\mathrm{NIH}=$ National Institutes of Health; WSDLI = Washington State Department of Labor and Industry.

compared SCS with structural reoperation and found substantial pain relief among $47 \%$ versus $11 \%$ of patients, respectively, with stability or decreased narcotic use noted in $87 \%$ of SCS patients and increased narcotic use noted in $42 \%$ of reoperation patients. There is recent evidence that implementation of this technology is more efficacious when done sooner after the patient develops neuropathic pain, with the propensity of different subspecialties to initiate referral for SCS being a significant contributor to variability in wait times. ${ }^{10}$ Cost-effectiveness studies have been performed on the cited Kumar et al. ${ }^{12}$ and North et al. ${ }^{19}$ RCTs. When compared with CMM, the incremental cost-effectiveness ratio was $\$ 5149$ per quality-adjusted life year, implying that it is a highly cost-effective intervention for restoring meaningful quality of life. ${ }^{9}$ When compared with spinal reoperation, SCS was the dominant intervention; it was both less expensive and more effective in PPNP patients. ${ }^{18}$
Levy and coworkers ${ }^{13}$ performed a nationwide study on neurological complications after using surgical paddles for SCS across all indications; the study involved about 44,857 patients. The rare complication for a spinal epidural hematoma (EDH) was observed in $0.19 \%$ of patients, two-thirds of whom exhibited substantial motor deficit. Further, sensory and motor deficits without EDH were observed in $0.1 \%$ and $0.13 \%$, respectively, suggesting either contusive injury or substantial space occupancy by the leads. While rare, these complications are not benign, and they certainly warrant discussion with patients upon deciding to implement this therapy for the management of disabling neuropathic pain.

Complication avoidance is important to consider in what is essentially an invasive surgical procedure for the management of treatment-refractory pain. Application of minimally invasive spine surgical techniques decreases the approach-related morbidity, limiting bone removal

TABLE 3. Complications related to spinal cord stimulator components

\begin{tabular}{|c|c|c|c|c|c|c|}
\hline \multirow[b]{2}{*}{ Authors \& Year } & \multirow[b]{2}{*}{$\begin{array}{c}\text { No. of } \\
\text { Patients }\end{array}$} & \multicolumn{5}{|c|}{ No. of Patients (\%) } \\
\hline & & $\begin{array}{l}\text { Lead Migrated or } \\
\text { Misplaced }\end{array}$ & IPG Failure & Wire Breakage & IPG Migration & Other \\
\hline Rigoard et al., 2015 & 76 & NR & & & & \\
\hline Al-Kaisy et al., 2014 & 83 & $5(6)$ & & & & \\
\hline Van Buyten et al., 2013 & 82 & $12(14)$ & & & & $2(2)$ \\
\hline Logé et al., 2013 & 21 & $1(5)$ & & $4(19)$ & & \\
\hline Kinfe et al., 2012 & 81 & $11(13)$ & & & & \\
\hline Turner et al., 2010 & 28 & $3(11)$ & & & & $1(4)$ \\
\hline Kumar et al., 2008 & 42 & $9(21)$ & & $4(10)$ & $1(2)$ & $3(7)$ \\
\hline Duyvendak, 2007 & 20 & $1(5)$ & & & & \\
\hline Oakley et al., 2006 & 56 & $11(20)$ & $1(2)$ & & & \\
\hline North et al., $2005^{20}$ & 20 & $1(5)$ & $1(5)$ & & & \\
\hline North et al., $2005^{19}$ & 33 & $3(9)$ & & & & \\
\hline
\end{tabular}

IPG = implantable pulse generator; $\mathrm{NR}=$ not recorded. 
TABLE 4. Complications related to SCS therapy

\begin{tabular}{|c|c|c|c|c|}
\hline \multirow[b]{2}{*}{ Authors \& Year } & \multirow{2}{*}{$\begin{array}{c}\text { No. of } \\
\text { Patients }\end{array}$} & \multicolumn{3}{|c|}{ No. of Patients (\%) } \\
\hline & & Loss of Therapeutic Effect & Pocket \& Local Pain & Nerve Irritation \\
\hline Rigoard et al., 2015 & 76 & & & \\
\hline Al-Kaisy et al., 2014 & 83 & $2(2)$ & $7(8)$ & \\
\hline Van Buyten et al., 2013 & 82 & $2(2)$ & $15(18)$ & $2(2)$ \\
\hline Logé et al., 2013 & 21 & $3(14)$ & & \\
\hline Kinfe et al., 2012 & 81 & & & \\
\hline Turner et al., 2010 & 28 & $4(14)$ & $7(25)$ & \\
\hline Kumar et al., 2008 & 42 & $5(12)$ & $5(12)$ & \\
\hline Duyvendak, 2007 & 20 & & $13(65)$ & \\
\hline Oakley et al., 2006 & 56 & & & \\
\hline North et al., $2005^{20}$ & 20 & $4(20)$ & & \\
\hline North et al., $2005^{19}$ & 33 & & & \\
\hline
\end{tabular}

during the laminotomy, operative duration, and associated blood loss. ${ }^{4,25}$ Local wound application of antimicrobial therapy at the surgical site may decrease infection rates for those leads implanted by more extensive laminectomy, although prospective randomized trials exploring this are lacking. ${ }^{2}$ While neurological complications remain rare, their avoidance is paramount because of the high rate of morbidity associated with contusive or compressive spinal cord injury. Preoperative assessment with MRI around the implant region is essential to ensure an adequate spinal canal cross-sectional area to accommodate the additional volume of the device. Bleeding risk for EDH occurrence remains even several days following surgery, and decisions about medications affecting coagulation should be carefully considered, particularly if their indication is primary prevention.

Techniques decreasing surgical invasiveness offer only advantage and should be implemented if they are within the armamentarium of the implanting surgeon. Neurophysiological monitoring is particularly important for implants placed under general anesthesia, to monitor for cord injury by altered somatosensory evoked potentials. Such a change should prompt the surgeon to either abort or alter the surgical plan. Common techniques to protect against electrode migration include anchoring devices to secure wires to ligamentous structures or fascia, and the use of strain-relief loops in the subcutaneous compartment to protect against device movement within the canal.

\section{Limitations}

This is a narrative review of prospective studies, 2 randomized and 9 observational. The rigor of data collection regarding complications is difficult to assure; however, this was done in all studies with high rates of follow-up and in a prospective fashion. Among these 11 studies, 6 were industry funded, 4 reported no funding source, and 1 was funded by national- and state-level peer-reviewed funding. Certainly there is potential for reporting bias, although this study reviewed prospectively collected complication data and not efficacy of the therapy, and may be less impacted by such support mechanisms.

TABLE 5. Biological complications of SCS

\begin{tabular}{|c|c|c|c|c|c|c|}
\hline \multirow[b]{2}{*}{ Authors \& Year } & \multirow[b]{2}{*}{$\begin{array}{c}\text { No. of } \\
\text { Patients }\end{array}$} & \multicolumn{5}{|c|}{ No. of Patients (\%) } \\
\hline & & $\begin{array}{l}\text { Psychiatric } \\
\text { Distress }\end{array}$ & $\begin{array}{c}\text { Wound } \\
\text { Complication }\end{array}$ & $\begin{array}{l}\text { Hematoma } \\
\text { or Seroma }\end{array}$ & Thrombosis & CSF Leak \\
\hline Rigoard et al., 2015 & 76 & $1(1)$ & $1(1)$ & & & \\
\hline Al-Kaisy et al., 2014 & 83 & & $6(7)$ & & & \\
\hline Van Buyten et al., 2013 & 82 & $5(6)$ & $5(6)$ & $5(6)$ & $1(1)$ & \\
\hline Logé et al., 2013 & 21 & & & & & \\
\hline Kinfe et al., 2012 & 81 & & & & & \\
\hline Turner et al., 2010 & 28 & & $4(14)$ & & & $1(4)$ \\
\hline Kumar et al., 2008 & 42 & & $4(10)$ & $3(7)$ & & \\
\hline Duyvendak, 2007 & 20 & & $2(10)$ & & & \\
\hline Oakley et al., 2006 & 56 & & $2(4)$ & & & \\
\hline North et al., $2005^{20}$ & 20 & & & & & \\
\hline North et al., $2005^{19}$ & 33 & & $1(3)$ & & & \\
\hline
\end{tabular}




\section{Conclusions}

The use of SCS devices to control PPNP can provide for improvement in pain and reduction in medication use among patients who failed to achieve benefit with structural spinal surgery for degenerative lumbar disease. Prospective studies formed the basis of this review and reveal a high rate of minor complications of which both patients and clinicians should be aware. Many of these require further surgical intervention to manage, including lead migration or implant infection, although the complication itself does not threaten patient life or function. The incidence of transient or permanent neurological deficit from spinal cord dysfunction is extremely rare but may require emergent neurosurgical intervention or carry substantial disability. Based on largely high-quality, prospective evidence, we find that SCS can be performed safely to manage the care of patients with PPNP.

\section{References}

1. Al-Kaisy A, Van Buyten JP, Smet I, Palmisani S, Pang D, Smith T: Sustained effectiveness of $10 \mathrm{kHz}$ high-frequency spinal cord stimulation for patients with chronic, low back pain: 24-month results of a prospective multicenter study. Pain Med 15:347-354, 2014

2. Amrani J: Intraoperative powdered vancomycin use with paddle lead placement. Neuromodulation 18:177-181, 2015

3. de Vos CC, Meier K, Zaalberg PB, Nijhuis HJ, Duyvendak $\mathrm{W}$, Vesper J, et al: Spinal cord stimulation in patients with painful diabetic neuropathy: a multicentre randomized clinical trial. Pain 155:2426-2431, 2014

4. Deer T, Bowman R, Schocket SM, Kim C, Ranson M, Amirdelfan K, et al: The prospective evaluation of safety and success of a new method of introducing percutaneous paddle leads and complex arrays with an epidural access system. Neuromodulation 15:21-30, 2012

5. Duyvendak W: Spinal cord stimulation with a dual quadripolar surgical lead placed in general anesthesia is effective in treating intractable low back and leg pain. Neuromodulation 10:113-119, 2007

6. Frey ME, Manchikanti L, Benyamin RM, Schultz DM, Smith HS, Cohen SP: Spinal cord stimulation for patients with failed back surgery syndrome: a systematic review. Pain Physician 12:379-397, 2009

7. Huang KT, Martin J, Marky A, Chagoya G, Hatef J, Hazzard MA, et al: A national survey of spinal cord stimulation trialto-permanent conversion rates. Neuromodulation 18:133140,2015

8. Kinfe TM, Schu S, Quack FJ, Wille C, Vesper J: Percutaneous implanted paddle lead for spinal cord stimulation: technical considerations and long-term follow-up. Neuromodulation 15:402-407, 2012

9. Kumar K, Rizvi S: Cost-effectiveness of spinal cord stimulation therapy in management of chronic pain. Pain Med 14:1631-1649, 2013

10. Kumar K, Rizvi S, Nguyen R, Abbas M, Bishop S, Murthy V: Impact of wait times on spinal cord stimulation therapy outcomes. Pain Pract 14:709-720, 2014

11. Kumar K, Taylor RS, Jacques L, Eldabe S, Meglio M, Molet $\mathrm{J}$, et al: The effects of spinal cord stimulation in neuropathic pain are sustained: a 24-month follow-up of the prospective randomized controlled multicenter trial of the effectiveness of spinal cord stimulation. Neurosurgery 63:762-770, 2008

12. Kumar K, Taylor RS, Jacques L, Eldabe S, Meglio M, Molet $\mathrm{J}$, et al: Spinal cord stimulation versus conventional medical management for neuropathic pain: a multicentre randomised controlled trial in patients with failed back surgery syndrome. Pain 132:179-188, 2007

13. Levy R, Henderson J, Slavin K, Simpson BA, Barolat G, Shipley J, et al: Incidence and avoidance of neurologic complications with paddle type spinal cord stimulation leads. Neuromodulation 14:412-422, 2011

14. Logé D, Vanneste S, Vancamp T, Rijckaert D: Long-term outcomes of spinal cord stimulation with percutaneously introduced paddle leads in the treatment of failed back surgery syndrome and lumboischialgia. Neuromodulation 16:537545, 2013

15. Mekhail NA, Mathews M, Nageeb F, Guirguis M, Mekhail MN, Cheng J: Retrospective review of 707 cases of spinal cord stimulation: indications and complications. Pain Pract 11:148-153, 2011

16. Meyerson BA, Linderoth B: Mechanisms of spinal cord stimulation in neuropathic pain. Neurol Res 22:285-292, 2000

17. Meyerson BA, Linderoth B: Mode of action of spinal cord stimulation in neuropathic pain. J Pain Symptom Manage 31 (4 Suppl):S6-S12, 2006

18. North RB, Kidd D, Shipley J, Taylor RS: Spinal cord stimulation versus reoperation for failed back surgery syndrome: a cost effectiveness and cost utility analysis based on a randomized, controlled trial. Neurosurgery 61:361-369, 2007

19. North RB, Kidd DH, Farrokhi F, Piantadosi SA: Spinal cord stimulation versus repeated lumbosacral spine surgery for chronic pain: a randomized, controlled trial. Neurosurgery 56:98-107, 2005

20. North RB, Kidd DH, Olin J, Sieracki JM, Farrokhi F, Petrucci L, et al: Spinal cord stimulation for axial low back pain: a prospective, controlled trial comparing dual with single percutaneous electrodes. Spine (Phila Pa 1976) 30:1412-1418, 2005

21. North RB, Kidd DH, Petrucci L, Dorsi MJ: Spinal cord stimulation electrode design: a prospective, randomized, controlled trial comparing percutaneous with laminectomy electrodes: part II-clinical outcomes. Neurosurgery 57:990-996, 2005

22. Oakley JC, Espinosa F, Bothe H, McKean J, Allen P, Burchiel $\mathrm{K}$, et al: Transverse tripolar spinal cord stimulation: results of an international multicenter study. Neuromodulation 9:192-203, 2006

23. Oakley JC, Prager JP: Spinal cord stimulation: mechanisms of action. Spine (Phila Pa 1976) 27:2574-2583, 2002

24. Rigoard P, Jacques L, Delmotte A, Poon K, Munson R, Monlezun $\mathrm{O}$, et al: An algorithmic programming approach for back pain symptoms in failed back surgery syndrome using spinal cord stimulation with a multicolumn surgically implanted epidural lead: a multicenter international prospective study. Pain Pract 15:195-207, 2015

25. Rigoard P, Luong AT, Delmotte A, Raaholt M, Roulaud M, Monlezun O, et al: Multicolumn spinal cord stimulation lead implantation using an optic transligamentar minimally invasive technique. Neurosurgery 73:550-553, 2013

26. Smits H, van Kleef M, Holsheimer J, Joosten EA: Experimental spinal cord stimulation and neuropathic pain: mechanism of action, technical aspects, and effectiveness. Pain Pract 13:154-168, 2013

27. Taylor RS: Spinal cord stimulation in complex regional pain syndrome and refractory neuropathic back and leg pain/ failed back surgery syndrome: results of a systematic review and meta-analysis. J Pain Symptom Manage 31 (4 Suppl):S13-S19, 2006

28. Taylor RS, De Vries J, Buchser E, Dejongste MJ: Spinal cord stimulation in the treatment of refractory angina: systematic review and meta-analysis of randomised controlled trials. BMC Cardiovasc Disord 9:13, 2009

29. Taylor RS, Taylor RJ, Van Buyten JP, Buchser E, North R, Bayliss S: The cost effectiveness of spinal cord stimulation in 
the treatment of pain: a systematic review of the literature. J Pain Symptom Manage 27:370-378, 2004

30. Turner JA, Hollingworth W, Comstock BA, Deyo RA: Spinal cord stimulation for failed back surgery syndrome: outcomes in a workers' compensation setting. Pain 148:14-25, 2010

31. Ubbink DT, Vermeulen H, Spincemaille GH, Gersbach PA, Berg P, Amann W: Systematic review and meta-analysis of controlled trials assessing spinal cord stimulation for inoperable critical leg ischaemia. Br J Surg 91:948-955, 2004

32. Van Buyten JP, Al-Kaisy A, Smet I, Palmisani S, Smith T: High-frequency spinal cord stimulation for the treatment of chronic back pain patients: results of a prospective multicenter European clinical study. Neuromodulation 16:59-66, 2013

33. Villavicencio AT, Leveque JC, Rubin L, Bulsara K, Gorecki JP: Laminectomy versus percutaneous electrode placement for spinal cord stimulation. Neurosurgery 46:399-406, 2000

34. Weinstein JN, Lurie JD, Tosteson TD, Tosteson AN, Blood EA, Abdu WA, et al: Surgical versus nonoperative treatment for lumbar disc herniation: four-year results for the Spine Patient Outcomes Research Trial (SPORT). Spine (Phila Pa 1976) 33:2789-2800, 2008

35. Weinstein JN, Lurie JD, Tosteson TD, Zhao W, Blood EA, Tosteson AN, et al: Surgical compared with nonoperative treatment for lumbar degenerative spondylolisthesis. fouryear results in the Spine Patient Outcomes Research Trial
(SPORT) randomized and observational cohorts. J Bone Joint Surg Am 91:1295-1304, 2009

36. Weinstein JN, Tosteson TD, Lurie JD, Tosteson A, Blood E, Herkowitz H, et al: Surgical versus nonoperative treatment for lumbar spinal stenosis four-year results of the Spine Patient Outcomes Research Trial. Spine (Phila Pa 1976) 35:1329-1338, 2010

\section{Disclosure}

The authors report no conflict of interest concerning the materials or methods used in this study or the findings specified in this paper.

\section{Author Contributions}

Conception and design: Shamji, Heary. Acquisition of data: Shamji, Westwick. Analysis and interpretation of data: Shamji, Heary. Drafting the article: Shamji, Westwick. Critically revising the article: Shamji, Heary. Reviewed submitted version of manuscript: Shamji, Heary.

\section{Correspondence}

Mohammed F. Shamji, Toronto Western Hospital, Division of Neurosurgery, WW4-446, 399 Bathurst St., Toronto, ON M5T 2S8, Canada.email: mohammed.shamji@uhn.ca. 